\title{
Does bioprospecting risk moral hazard for science in the Antarctic Treaty System?
}

\author{
Alan D. Hemmings* \\ Gateway Antarctica Centre for Antarctic Studies and Research, University of Canterbury, Private Bag 4800, \\ Christchurch 8020, New Zealand
}

\begin{abstract}
Bioprospecting in Antarctica has been generated in the course of, and is largely driven by, the success of Antarctic science, which has been given an entrenched and privileged role in the international Antarctic governance regime provided by the Antarctic Treaty System over the past half century. However, bioprospecting represents a new departure for Antarctic science in that for the first time it is not external to a resource activity, and capable of providing disinterested and independent advice on the management of that activity, but an active participant in the activity. Without some institutional separation of science as actor from science as independent advisor, bioprospecting may risk moral hazard for science in the Antarctic Treaty System.
\end{abstract}

KEY WORDS: Bioprospecting $\cdot$ Biological prospecting $\cdot$ Antarctica $\cdot$ Antarctic Treaty System Resale or republication not permitted without written consent of the publisher

\section{INTRODUCTION}

Bioprospecting has been underway in Antarctica since the late 1980 s, but first came to the attention of the Antarctic Treaty System (ATS) in 1999 in a paper on scientific research tabled at an annual Antarctic Treaty Consultative Meeting (ATCM) (SCAR 1999). In that paper and thereafter in ATCMs, the synonym 'biological prospecting' has been employed. Discussion of Antarctic bioprospecting as a technical and scientific issue is evident in the literature from the early 2000s on (e.g. Bowman 2001, Nichols 2001). The literature on Antarctic bioprospecting as a legal and policy issue essentially begins with Jabour-Green \& Nicol (2003) and is now substantial. Consideration of bioprospecting within the Antarctic political fora (primarily at ATCMs) has been continuous since 2002 (Hemmings 2005, 2009a). Whilst no specific legally binding regulatory structure has been agreed for the activity, there are arguments and precedents for doing this (Hemmings \& RoganFinnemore 2008) and some Antarctic Treaty Consultative Parties favour doing so. Others do not, and in a system where decision-making requires consensus there appears no likelihood of the sort of regulatory responses to bioprospecting that the ATS has elaborated for previous resource/commercial activities eventuating in the near-term. There are complex and potentially significant synergies between bioprospecting and other important Antarctic policy issues, such as those associated with the Antarctic and sub-Antarctic continental shelf (Hemmings \& Stephens 2009, in press). More generally, there are legitimate questions about whether bioprospecting necessarily only entails the slight environmental risk that its protagonists assume (Hemmings \& Rogan-Finnemore 2005, p. 242), and around the geopolitical consequences of a new resource activity for the stability of the Antarctic political regime, both internally and in relation to the wider international community (Hemmings \& Rogan-Finnemore 2008, p. 537). An overview of bioprospecting issues in the Antarctic (and Arctic) is provided in Leary (2009).

This paper examines a facet of the bioprospecting issue that has not been given substantive treatment before - the role of 'science' as a participant actor in the debate conducted within the ATS about the appropriate response to bioprospecting. Graham (2005, p. 46) touched upon the relationship between science and industry, and cast 'biotechnologists as the new "masons", but the focus was not on the role of science and scientists in the ATS as such. Hemmings \& Rogan- 
Finnemore (2005) canvassed some elements which are developed further here.

The Antarctic political arrangements give particular weight to science as both a privileged use of the region and as the necessary underpinning for its protection and management. This situation arises through several contingencies, whose detailed examination is outside the purview of the present paper. These include the following: (1) the historic profile of scientific enquiry in the region from its earliest exploration, through the socalled 'Heroic-era' (Fogg 1992), to the International Geophysical Year (IGY) which immediately pre-dated the negotiation of the Antarctic Treaty (Fogg 1992, p. 168-176; Belanger 2006, p. 29-46); and (2) the construing of the scientific project as one that could transcend politics (including the vexed issues around Cold War confrontation and the challenges of positions on territorial sovereignty) and provide an acceptable context for national and multinational activity in the Antarctic Treaty Area. Implicitly, science was seen as objective and (critically) disinterested at the geopolitical level. Science was the glue holding the Antarctic political dispensation together and 'the basic international currency for practical influence in Antarctic affairs' (Herr \& Hall 1989, p. 13). However, as first a continent more poorly known and understood than the others, and then more recently recognised as critical to the understanding of global processes including climate change, there has also been an enduring validity to the popular casting (e.g. Lewis 1965) of Antarctica as a 'continent for science'.

For the purposes of this paper, Antarctica is taken as the entire area south of latitude $60^{\circ} \mathrm{S}$. This covers the continent, surrounding Antarctic islands and ocean covered by the 1959 Antarctic Treaty and the 1991 Protocol on Environmental Protection to the Antarctic Treaty (Madrid Protocol) - the area commonly referred to as the Antarctic Treaty Area. It also covers the Southern Ocean as defined by the International Hydrographic Organisation. However, restriction to this area means that a very large area, north of $60^{\circ} \mathrm{S}$ and up to the Antarctic Convergence or Polar Front (generally taken as the appropriate scientific boundary for the Southern Ocean), and a large part of the marine area covered by another component ATS instrument, the 1980 Convention on the Conservation of Antarctic Marine Living Resources (CCAMLR), are omitted. The saving grace is the easing of complexity, since an area of coverage extending to the Polar Front would include some sub-Antarctic islands which are subject to coastal state jurisdiction. Of course, whichever area was chosen, the geopolitical context would necessarily include the fact that several key global instruments with a bearing on bioprospecting also penetrate the Antarctic Treaty Area: the 1982 United Nations Convention on the Law of the Sea and the 1992 Convention on Biological Diversity (CBD). However, this paper is confined to the ethical matters arising in the context of the ATS south of latitude $60^{\circ} \mathrm{S}$.

\section{SCIENCE IN THE ANTARCTIC TREATY SYSTEM}

Notwithstanding a diversification of activities and actors in Antarctica over the past 2 decades as globalism impacts on Antarctica (Hemmings 2007, 2009b), science remains the principal human activity ashore there. In the marine environment, whilst overtaken (in numbers of ships and length of the operating season) by marine harvesting, it remains a significant part of the activity. National Antarctic programmes are still overwhelmingly concerned with the conduct of science; this means that most facilities and equipment are directed towards science support. Domestic Antarctic policymaking generally involves many agencies, but invariably includes those responsible for national science and Antarctic programmes, and in some states these are the lead agencies for national Antarctic decision-making. As a consequence, scientists and science-managers (not necessarily having coincident interests, but generally sharing a common language) have from the start been significant participants in state, observer and expert delegations to ATS fora - see for example the list of participants at I ATCM (Australia 1961) — and in the secretariat structures now supporting the formal and informal Antarctic institutions. So, the engaged Antarctic policy community is well colonised by people who would see themselves as in some sense scientists. This is a not inconsiderable factor in determining the framing adopted and the sorts of approaches that may be viewed as appropriate for particular Antarctic policy issues. Of course, policy development generally involves an iterative relationship with another community - the diplomatic and legal experts who form the other half of delegations and (formally at least) often constitute the higher echelons of national decisionmaking.

The more substantive basis for the operational influence of science in the ATS is found in the institutionalised position that it is given in the legal instruments that make up the ATS, and in the practice of states within the institutions of the ATS in relation to their preferred sources (and types) of advice.

\section{Science and the Antarctic legal instruments}

The 1959 Antarctic Treaty explicitly continues the freedom of scientific investigation and scientific cooperation of the IGY (Preamble and Article II), sanctions 
the use of military personnel and equipment solely in support of scientific research and other peaceful purposes (Article I.1), establishes scientific exchange as a keystone of international cooperation (Article III), and requires that scientific personnel and others on exchange are subject only to the jurisdiction of their own state (Article VIII). ATCMs are established to further consider, inter alia, the facilitation of scientific research and international scientific cooperation (Article IX.1), and any subsequent Contracting Parties to the treaty are able to participate in ATCMs only 'during such time as that Contracting Party demonstrates its interest in Antarctica by conducting substantial scientific research activity there, such as the establishment of a scientific station or the despatch of a scientific expedition' (Article IX.2).

The 1980 CCAMLR, in contrast to the Antarctic Treaty (and the Madrid Protocol; below), makes little reference to science in the early parts of the instrument. Its purposes after all include creating the mechanism whereby marine living resources may be exploited. It is not an instrument purposefully promoting science in the way that the Antarctic Treaty does. However, the connections made with the Antarctic Treaty, and the casting of the convention as one based upon rational use (Article II.2) and preserving ecosystem integrity (Articles I and II) clearly presume an important role for science in achieving this. The operational role of science in CCAMLR is made explicit with the establishment of a Scientific Committee for the Conservation of Antarctic Marine Living Resources (Article XIV), with this Scientific Committee given specific directions as to its functions (Article XV) and administrative capacity (Article XVI). Both the Commission and Scientific Committee are to cooperate with various bodies, including the Scientific Committee for Antarctic Research (SCAR) (Article XXIII.3).

The 1991 Protocol on Environmental Protection to the Antarctic Treaty (Madrid Protocol) reiterates the importance of science (Preamble, and Articles 2, 3, 6 and 7) and embeds Antarctica 'as an area for the conduct of scientific research' (Article 3) as one of the key values to be secured by the Protocol. SCAR suffered a relative loss of influence within the ATS as a result of it being perceived as partisan in the course of the debate around the acceptability of Antarctic mining during negotiation of the 1988 Convention on the Regulation of Antarctic Mineral Resource Activities (CRAMRA). However, when that convention was subsequently abandoned in favour of the Madrid Protocol, and a separate advisory Committee for Environmental Protection (CEP) was established, SCAR was one of only 2 Observers in the CEP designated in the instrument (Article 11). Article 12 specifically mandates CEP consultation with SCAR.

\section{Scientific Committee for Antarctic Research}

The special (later Scientific) Committee for Antarctic Research (SCAR) was established in 1958, in the midst of the IGY, as a body of the International Council of Scientific Unions (ICSU) to form the international coordinating structure for Antarctic science. At I ATCM in 1961, whilst not formally represented, SCAR was already, as that meeting's Recommendations I-I and IIV indicate, effectively if informally the key scientific mechanism for ATCPs. The first substantive Antarctic environmental development, the proto-environmental instrument of the 1964 Agreed Measures for the Conservation of Antarctic Fauna and Flora, adopted under Recommendation III-VIII, was essentially developed by SCAR, and SCAR is explicitly referred to in the 5th recital of its Preamble. SCAR itself recognises the Agreed Measures as one of its major achievements in the ATS (SCAR 2008).

In the meetings of CCAMLR, SCAR was granted formal status as an Observer at the First Meeting of the Commission in 1982 (CCAMLR Commission 1982) and took this up from the Second Meeting in 1983 (CCAMLR Commission 1983). With the ATCM administrative reorganisation of Recommendation XIII-2 (Belgium 1985), SCAR became one of 2 Observers granted permanent status at the ATCM, commencing at XIV ATCM (the meetings were at this date biennial) in 1987 (Brazil 1987).

With the Madrid Protocol, as noted above, SCAR has an entrenched role in the CEP. SCAR is often askedby both the CEP and the ATCM - to provide advice on specific scientific/technical issues relating to the operation of the Madrid Protocol, in addition to the advice it provides on the wider project of scientific engagement and international scientific cooperation in Antarctica. Its influence is manifestly less direct in relation to marine harvesting issues, where separate and specialised advisory bodies have emerged under CCAMLR, and where the substantially commercial focus of the prime activity means that particular applied science expertise is sought by national delegations. SCAR is, after the CRAMRA-induced hiatus, a player in the ATCM and CEP. It is a more marginal player in the fora of CCAMLR. The question may be whether this reflects the significantly different purposes of these 2 spheres of the operational ATS (managing international cooperation and the key values of peace, science and the environment on the one hand, and rational marine resource exploitation on the other), or whether other explanations might be found. If the former, this may have some bearing in relation to the role and influence of SCAR in other areas of Antarctic commercial/resource activity as they arise, most pertinently here in relation to bioprospecting. 


\section{HISTORIC ASSUMPTIONS AROUND SCIENCE IN ANTARCTICA}

Science is embedded in the system of legal instruments and institutions that comprise the ATS, and this arose through particular historical contingencies. The geopolitical utility of this arrangement was that science provided a neutral common ground irrespective of nationalist and ideological stances. The implicit assumption was that Antarctic science was a thing apart, a means of benignly meeting national interests in real-estate, sovereignty, and resource potential (Hemmings \& Rogan-Finnemore 2005, p. 235) without rattling the bars of the Antarctic political dispensation. The fact that it was international, involved generally shareable goods, and was inherently collaborative made it the necessary balm in a region where territorial sovereignty was contested and as a consequence the allocation of resources was plainly going to be problematical. Further, this role for science was embedded before the possibility of resource exploitation (apart from whaling, which was anyway subject not to the ATS but to the 1946 International Convention for the Regulation of Whaling and its International Whaling Commission) arose in Antarctica. The shape of the Antarctic regime, and the consequential place of science, would likely have been rather different if substantial Antarctic resource activities had been underway at the commencement of the ATS.

It was plainly the case that once the ATS established itself as a system predicated on scientifically informed advice, this advice would be called upon in relation to each subsequent development that the system faced. Inevitably, the science and the involved science community would evolve with the system and the issues. Indeed this is what happened. As the ATS successively engaged with sealing (the 1972 Convention for the Conservation of Antarctic Seals [CCAS]), marine harvesting (CCAMLR), mineral resources (CRAMRA), environmental protection (Madrid Protocol), and more recently tourism, the science around these issues became part of Antarctic science. It should surprise nobody that since the issues were themselves political, and at various stages quite contested policy areas, the science (or at least the scientists and scientific communities involved) were also politicised. In each case, communities of scientists, and even some scientific disciplines (or subsets thereof) saw themselves as winners or losers in the potential policy outcomes.

Antarctic geological and other earth-sciences research saw an increase in support during the late 1970s and 1980s as CRAMRA was underway, and a decrease in support (and an even more striking reduction in profile) once CRAMRA had been aban- doned and parties had reached consensus on a prohibition of mineral resource activities in Article 7 of the Madrid Protocol, even though scientific research in this field was exempted from the prohibition. The biological sciences were (post-Protocol) more favoured, as substantive contributors to the newly required need for environmental data, and perhaps as a reassurance to domestic constituencies that the resource interests had really waned. To complete this brief sketch it may be noted that for states which by virtue of their Antarctic territorial claims see themselves there as 'coastal states', in the terms of the United Nations Convention on the Law of the Sea, the perceived need to acquire data for the Article 76 submissions to the Commission on the Limits of the Continental Shelf led to new support for marine earth-sciences research in Antarctica from the late 1990s. The arrival of marine harvesting in Antarctic waters stimulated a massive increase in the science focussed on stock abundance and distribution, and particular target taxa, alongside the ecosystem focus that one associates with CCAMLR responsibilities. Whilst CCAMLR pre-dated, and is still happily more than, a Regional Fisheries Management Organisation (RFMO), it has spawned the predictable community of fishery-friendly science.

Whatever interesting challenges these issues posed, and whatever natural interests in particular outcomes particular parts of the Antarctic science community had, science as a project still remained essentially distinct from the resource issue itself. Parts of the scientific community might well be beneficiaries of particular industries, but they were not generally prime actors in those industries. Whilst their science could facilitate particular resource extraction, it did not generally generate the intellectual property upon which the industry was founded - beyond the general fact that in a place like Antarctica, knowledge is of course a critical foundation for anything. There will no doubt be exceptions, but as a generally applicable proposition it can be suggested that a rather different situation to that previously obtaining arose with bioprospecting.

With bioprospecting, science is no longer just the external advisor to other actors and an independent analyst and interpreter of significance, but the stimulant for the activity in the first place and active conductor of that activity. In the deconstructed world of intellectual property, the scientist or science group is much more likely to have a direct pecuniary interest in the bioprospecting endeavour. At the extreme, the principal investigator may now also be a director, or even a founder, of the company seeking to realise the benefits, and thus a direct beneficiary in a way generally not seen before. Bioprospecting is grounded in, and has grown out of, Antarctic scientific interests and 
research capabilities; indeed, at one end it may still be essentially indistinguishable from conventional science, whilst at the other it is clearly an industrial activity. It is not just the latest resource-access issue to hit the Antarctic regions but an activity with particular implications for science as a central pillar of the current Antarctic political regime (Hemmings \& RoganFinnemore 2005, p. 235). This is a new departure and has a number of implications for the standing of Antarctic science and the privileged role of science in general in the ATS.

\section{MORAL HAZARD OF ANTARCTIC BIOPROSPECTING}

The concept of moral hazard arose in the context of insurance to capture the apparent paradox of insurance plans actually encouraging behaviour that increased the risk of loss, and developed a wider economic usage around misallocation of resources (Marshall 1976). More recently it has acquired a currency in the discourse around the bailout of financial institutions (Stiglitz 2006, p. 217). Its advantages as a term are that despite the inclusion of the word 'moral', and the often pejorative sense in which it is employed, formally it can be argued to be a value-neutral concept (Dembe \& Boden 2000). What is intended here is a usage that captures the systemically arising (albeit perhaps unintended) consequences of science's particular privileged position in the ATS, leading to insulation against examination of the full range of consequences of an activity (bioprospecting) specifically and closely coupled with science. Whilst this usage does not presume to formally interpret the alleged moral hazard in a pejorative way, it is plainly predicated upon a concern that there is a fundamental conflict of interest here that has hitherto not even been recognised, let alone addressed.

\section{Themes around Antarctic bioprospecting}

The policy positions of ATCPs in relation to bioprospecting are not monolithic and arise from a number of considerations. These include (1) national economic opportunity, (2) consistency with the Antarctic Treaty and other norms of Antarctic engagement, (3) the state of development of metropolitan bioprospecting policy, (4) the question of precedent creation, which may have consequences in other international and domestic fora, and (5) the implications of any regulatory developments around bioprospecting in international (non-ATS) fora, which may also apply in the Antarctic Treaty area.
However, also contributing is the advice that 'the state' receives from its science agencies and advisors. In the course of the unfolding of the Antarctic bioprospecting discourse over the past decade, certain recurrent themes are evident in the stances of some of the key communities:

(1) Scientists directly involved in bioprospecting.

- The benefits of the activity are argued on the basis of the best possible outcomes: the moral imperatives which cannot be foregone (the cure for cancer argument) and/or the potential economic returns on Antarctic investment

- In parallel, that most research will not lead to a commercially realisable product, which whilst true also has the effect of downplaying any ill-effects of the activity

- That environmental effects will be either non-existent or very minor

- That the activity is in fact science and that surely no sane person proposes to constrain science in Antarctica given its historic role there.

(2) National programmes.

- That constraints on bioprospecting will kill an incipient golden goose, since this is one area where they can tell politicians that Antarctic research can generate income, rather than just costing the taxpayer money

- That if this is where the cutting edge of science is, they do not want to lose any competitive advantage to other programmes or states

- That they do not have clarity about benefit sharing within their programme, and this is a more immediate focus for their attention

- That administratively and methodologically it is complex, expensive and perhaps even bothersome to try and collect information about what constitutes bioprospecting above a very basic level

- That until there is a demonstrable problem, this issue does not need the attention.

(3) SCAR.

- SCAR is plainly alert to the scale of the activity and its implications for the larger project of international scientific cooperation in the Antarctic

- Its concerns appear to include the risk that bioprospecting will generate commercially sensitive information, which its owners will not necessarily wish to share, and that this will challenge the open access approach to scientific information seemingly required by Article III. 2 of the Antarctic Treaty: 'scientific observations and results from Antarctica shall be exchanged and made freely available'

- As a non-state entity, SCAR is free to express its views without particular national-interest concerns. However, since SCAR's positions are arrived at through negotiating amongst its members who are 
still nationally grounded, where there are divergent positions on the issue it may be under some practical constraints on how it proceeds

- Whilst SCAR has shown an early and sophisticated understanding of the issues that might arise as a result of bioprospecting, it is unreasonable to expect it to be entirely autonomous in its stances - and this despite the fact that its present sub-groups and prime officers are still drawn from a broad range of Antarctic science and not from a bioprospecting-dominated cohort.

\section{How deep is the problem?}

A reasonable rejoinder to these points would be the argument that even if this is all true (and no doubt others will contest some or all of it), not all Antarctic science is dominated by bioprospecting interests; scientists from other disciplines who are concerned are quite contrary enough to pose alternative perspectives and, influential as they are, the ATS is not solely controlled by scientists anyway. There is, on this basis, nothing to prevent the ATS from recognising the particular vested interests of some parts of the science community and litigating appropriate responses.

This is true, up to a point. The difficulty is that it is likely to kick-in only at a much higher level of concern about bioprospecting than we presently see - for all the usual reasons, e.g. higher order competitors for immediate attention, technical and administrative complexity, the absence of a clear-cut catastrophe attaching to the issue. In addition, there is the generic difficulty of resistance to developing new initiatives within the ATS in relation to anything, induced by globalism's challenge to Antarctic exceptionalism (Hemmings 2009b). If that holds, then approaches in Antarctica are left either to the emergence of global norms, or to the workings of the market. So, any initial difficulties in relation to the capacity of Antarctic science to give particular sorts of advice are compounded by the wider difficulties of reaching system-wide Antarctic outcomes.

Although it is not the purpose of this paper to enter into a detailed assessment of the challenges or promises of Antarctic bioprospecting, it is plainly necessary to at least itemise the considerations underlying the concern about moral hazard. The concerns fall into 3 main classes of risk: (1) risk to the environment; (2) risk to the scientific project in Antarctica; and (3) risk to the geopolitical stability of the Antarctic political arrangements.

Risk to the environment is as yet unproven. It is a reasonable assumption that this activity poses some risk, but the scale and intensity of actual impacts will de- pend on the particularities of the case. In the Madrid Protocol, we probably have a reasonable basis for managing the activity. The difficulty is probably greater in the marine environment, in large part because of the lack of certain key environmental management tools (especially in relation to Environmental Impact Assessment) under CCAMLR, and the uncertainties of jurisdiction across ATS and global instruments. In the present author's view, whilst there may be some problems, risk to the environment is probably not the most serious issue.

Risk to the scientific project in Antarctica includes general risks, such as the public disrepute that would likely attach to all Antarctic science if any one part causes an outrage there. What would constitute an outrage is necessarily speculative, but were, for example, the penetration of a sub-glacial lake to be seen to be driven by bioprospecting interests and that penetration resulted in some demonstrable high profile environmental damage, that might generate such outrage. More immediately problematical may be the risk posed to international scientific and associated logistical cooperation. Hitherto, with most Antarctic science (at least ashore) being non-commercial, the Antarctic Treaty's injunction to cooperate has been relatively straightforward to comply with. It is one of the great successes of the ATS. What happens however if the context now becomes one of potential commercial competitors based upon bioprospecting resources and associated intellectual property? Is this likely to have no effect on cooperation? A further development of this risk would be any effective failure to honour the Article III.2 obligations of the Antarctic Treaty already mentioned. In the longer term, were bioprospecting to become a major stream of Antarctic science, one would expect to see as one of the consequences the rise to influence of bioprospecting specialists within national and international Antarctic science structures (including SCAR). This would, presumably, have some bearing on the interests, priorities and flavour of these institutions.

Risk to the geopolitical stability of the Antarctic political arrangements is, whilst probably not an immediate risk, one that in the medium-term may be the most worrying. The ATS contained the challenges to its regional hegemony in the 1980s when it abandoned CRAMRA and adopted in its stead the Madrid Protocol. That effectively excised that resource issue. Although fishing and tourism have developed substantially in the period since, the first is managed by CCAMLR which has shown a capacity to absorb new members from the Global South and elsewhere, and the second is a resource activity of a rather different sort to the usual extractive industries. Bioprospecting seems potentially capable of reinvigorating the debate between the ATS and the Global South about appro- 
priation of the global commons (Hemmings \& RoganFinnemore 2008). These are early days, but the interest of the CBD in Antarctic bioprospecting has clearly worried some ATCPs since it challenges the ATS's interest in maintaining the principle of regional leadership (although as already noted, in practice this has fallen into disuse). The scaled-up version of the move to more competitive Antarctic stances noted in relation to the scientific project in Antarctica is that the parties to the ATS find themselves more competitive amongst themselves in a geopolitical sense. With the very complex Antarctic juridical arrangements, the tensions between claimants and non-claimants (and between some claimants), great disparities of technology and wealth between first-rate powers and smaller states, even a relative shift on the continuum between competition and cooperation could alter the present balance of the ATS.

None of this may eventuate, and even if it does it may unfold quite slowly and be adequately buffered by other and enduring common interests. But to accept that these risks are presently largely speculative is not to accept that there is no duty to try and anticipate them and preclude them. The Antarctic is some $10 \%$ of the planet, and the present levels of human cooperation and collegiality there are high. These should not lightly be risked.

\section{Avoiding or containing the problem}

The question therefore arises: What can be done? It is not a case of the centrality of science in the ATS suddenly becoming inappropriate. Far from it, our safety depends upon the understanding and prediction of climate-change, and the Antarctic provides perhaps our most important laboratory in this regard. The press of other activities in Antarctica already challenges the supposed priority of science there in some locations. It is critical that responses distinguish between science as an objective user of the Antarctic for significant public goods, and the more parochial self-interests around the margins of particular scientific activities. Bioprospecting is plainly not an inappropriate activity per se, and some of its benefits may be extremely important. Further, the debate around bioprospecting in the Antarctic Treaty Area is obviously broader than just a discourse on the ethics of scientific engagement under consideration here. Any regulatory mechanisms that arise can be expected to reflect this reality. But for the wider benefit, there does (whatever else we need to agree) appear to be a case for distinguishing between the personal and the general benefits accruing through bioprospecting in Antarctica. A sort of dualism in our evaluation of the claimed merits of bioprospecting seems reasonable.
In fact, the ATS has some precedents for dualism in its treatment of particular issues, which could be extended to bioprospecting too. Under the Antarctic Treaty it has distinguished between military activities per se (which it prohibits) and military equipment, expertise and personnel in support of peaceful purposes, including science (which it allows). Under the 1964 Agreed Measures for the Conservation of Antarctic Fauna and Flora, it gave substantial additional protection to fur seals and the Ross Seal, as Specially Protected Species, but allowed permits for the taking (including killing) of these for 'compelling scientific purpose'. It has distinguished between biological research on seals and their commercial hunting (under CCAS), and between scientific research and the prohibition of minerals resource activity (under the Madrid Protocol) (Hemmings \& Rogan-Finnemore 2005, p. 235). Without purporting to definitive framing here, the ATS could elaborate arrangements that allowed a similar access to biodiversity for scientific and small-scale commercial activity distinct from more fully industrial bioprospecting. It may be the case that establishing meaningful cut-off points between putative 'scientific research', 'small-scale' and 'industrial' bioprospecting would pose some challenges. These need not prove insuperable, assuming of course that it is possible to adopt any regulatory response to bioprospecting in the ATS. The aim, as with the earlier dualisms, would be to enable the benefits of certain levels of activity without opening the door to potentially more problematic levels, which challenge the stability of the system.

In relation to the role of science in the ATS, some new responses are probably called for in the case of bioprospecting. Here, for the first time, science wears 2 hats - its traditional Antarctic bonnet, and the hardhat of commercial self-interest. Some formal mechanisms to avoid conflict of interest seem called for, and some deliberate mechanism to ensure that the interests of science as exploiter are not laundered through its standing as privileged participant in the ATS. As in so many other areas, the maintenance of a viable Antarctic Treaty System will require us to periodically update it and not blithely assume that mechanisms established half a century ago will suffice.

Acknowledgements. My thanks to David Leary for his encouragement to submit this paper, and the stimulant of his own insightful papers on bioprospecting in the polar regions. Particular thanks are due to my friend and colleague Michelle Rogan-Finnemore, with whom previous work on Antarctic bioprospecting has been conducted, and many of the ideas expressed here first discussed. Thanks are extended to the 3 anonymous reviewers of the manuscript for their very helpful comments. Of course, none of these people should be implicated in the positions adopted by the author in this paper. 


\section{LITERATURE CITED}

Australia (1961) Report of First Consultative Meeting, Canberra

Belanger DO (2006) Deep Freeze: The United States, the International Geophysical Year, and the origins of Antarctica's Age of Science. University Press of Colorado, Boulder, $\mathrm{CO}$

Belgium (1985) Recommendation XIII-2 Operation of the Antarctic Treaty System: Overview. In: Final Report of the Thirteenth Antarctic Treaty Consultative Meeting, Brussels, p 34-35

Bowman JP (2001) Antarctica a global 'hot spot': biodiversity and biotechnology. In: Looking south-managing technology, oportunities and the global environment. Australian Academy of Technological Sciences and Engineering, Parkville, p 85-90.

Brazil (1987) p 1 In: Final Report of the Fourteenth Antarctic Treaty Consultative Meeting, Rio de Janeiro

CCAMLR (Convention on the Conservation of Antarctic Marine Living Resources) Commission 1982. Report of the First Meeting of the Commission. CCAMLR Secretariat, Hobart

CCAMLR (Convention on the Conservation of Antarctic Marine Living Resources) Commission 1983. Report of the Second Meeting of the Commission. CCAMLR Secretariat, Hobart

Dembe AE, Boden LI (2000) Moral hazard: a question of morality? New Solut 10:257-279

Fogg GE (1992) A history of Antarctic science. Cambridge University Press, Cambridge

Graham A (2005) Environmental, ethical and equity issues. In: Hemmings AD, Rogan-Finnemore M (eds) Antarctic bioprospecting. Gateway Antarctica Special Publication Series Number 0501, Christchurch, p 41-68

Hemmings AD (2005) A question of politics: bioprospecting and the Antarctic Treaty System. In: Hemmings AD, Rogan-Finnemore M (eds) Antarctic bioprospecting. Gateway Antarctica Special Publication Series Number 0501, Christchurch, p 98-129

Hemmings AD (2007) Globalisation's cold genius and the ending of Antarctic isolation. In: Kriwoken LK, Jabour J, Hemmings AD (eds) Looking south: Australia's Antarctic agenda. Federation Press, Leichhardt, p 176-190

Hemmings AD (2009a) Biological prospecting in the Antarctic Treaty Area. Invited opening paper: Intergovernmental Meeting of Experts on Biological Prospecting in the Antarctic Treaty Area. Baarn, 3-5 Feb

Editorial responsibility: David Leary, Sydney, New South Wales, Australia
Hemmings AD (2009b) From the new geopolitics of resources to nanotechnology: emerging challenges of globalism in Antarctica. Yearbook of Polar Law 1:55-72

Hemmings AD, Rogan-Finnemore M (2005) The issues posed by bioprospecting in Antarctica. In: Hemmings AD, Rogan-Finnemore M (eds) Antarctic bioprospecting. Gateway Antarctica Special Publication Series Number 0501, Christchurch, p 234-244

Hemmings AD, Rogan-Finnemore M (2008) Access, obligations and benefits: regulating bioprospecting in the Antarctic. In: Jeffery MI, Firestone J, Bubna-Litic K (eds) Biodiversity Conservation, Law + Livelihoods: Bridging the North-South Divide. Cambridge University Press, New York, p 529-552

Hemmings AD, Stephens T (2009) Australia's extended continental shelf: What implications for Antarctica? Public Law Review 20:9-16

Hemmings AD, Stephens T (in press) The extended continental shelves of sub-Antarctic islands: implications for Antarctic governance. Polar Rec (Gr Brit)

Herr R, Hall R (1989) Science as currency and the currency of science. In: Handmer J (ed) Antarctica: policies and policy development. Centre for Resource and Environmental Studies, Australian National University, Canberra, p 13-24

Jabour-Green J, Nicol D (2003) Bioprospecting in areas outside national jurisdiction: Antarctica and the Southern Ocean. Melbourne Journal of International Law 4:76-111

Leary D (2009) Bioprospecting in Antarctica and the Arctic. Common challenges? Yearbook of Polar Law 1:145-174

Lewis RS (1965) A continent for science. Secker \& Warburg, London

Marshall JM (1976) Moral hazard. Am Econ Rev 66:880-890

Nichols DS (2001) Case studies of biotechnology opportunities in Antarctica. In: Looking south - managing technology, opportunities and the global environment. Australian Academy of Technological Sciences and Engineering, Parkville, p 93-105

SCAR (Scientific Committee on Antarctic Research) (1999) Scientific research in the Antarctic. Information Paper 23. XXIII Antarctic Treaty Consultative Meeting, Lima

SCAR (Scientific Committee on Antarctic Research) (2008) Major SCAR inputs to the Antarctic Treaty System (based on SCAR Report 29) www.scar.org/about/ standingcommittees/antarctictreatysystem/SCAR_Inputs_to_ATS.pdf (last accessed 15.11.09)

Stiglitz J (2006) Making globalization work. Allen Lane, London

Submitted: November 30, 2009; Accepted: January 12, 2010 Proofs received from author(s): March 16, 2010 